\title{
Platform Work and the COVID-19 Pandemic
}

\author{
Uma Rani ${ }^{1} \cdot$ Rishabh Kumar Dhir $^{1}$ \\ Published online: 6 October 2020 \\ () Indian Society of Labour Economics 2020
}

\begin{abstract}
Platform business models emerged with the growth of the Internet in the 1990s and are conceptualized as two- or multi-sided markets, as they facilitate exchange between service providers, clients (business) and workers. This article focuses on the impact of COVID-19 on digital labour platforms, such as freelance online web-based platforms and location-based platforms (transportation and delivery platforms), which have grown exponentially over the past decade. The COVID-19 pandemic exposed immediately some of the vulnerabilities that the workers in the platform economy were facing as they were declared as part of the 'emergency services', and this note explores their conditions during the pandemic.
\end{abstract}

Keywords COVID-19 · Digital labour platforms · Digital economy · Platform work · Labour rights $\cdot$ Decent work

\section{Introduction}

Platform business models emerged with the growth of the internet in the 1990s. Platform businesses are conceptualized as two- or multi-sided markets, and they facilitate exchange between service providers, clients (business) and workers (UNCTAD 2019; Teece 2017; Evans and Gawer 2016). For instance, the most widespread two-sided markets are transportation platforms, where customers (riders) are matched with drivers, and freelance or microtask or competitive programming platforms, wherein clients (firms) are matched with workers or a crowd of programmers. The common three-sided market is the delivery platform, wherein the three parties-business partners (grocery or restaurants), the delivery worker and the customers-interact with each other, and the platform facilitates this exchange. These models feature a peculiar governance structure and a set of standards and protocols that facilitate interactions between the different users (clients, customers and workers) which are different from traditional business. The interactions between users on

Uma Rani

amara@ilo.org

1 International Labour Office, Geneva, Switzerland 
the platform are controlled and coordinated by the rules and standards that are laid down in platforms' terms of service agreements that are unilaterally determined by the platforms, which allows them to scale so as to unleash network effects (Hagel 2015). This strategy allows them to have a dominant position in the market, as is evident from Uber which operates in 69 countries. In this short piece, we will focus on the impact of COVID-19 on digital labour platforms, such as freelance online web-based platforms and location-based platforms (transportation and delivery platforms), which have grown exponentially over the past decade. The COVID-19 pandemic exposed immediately some of the vulnerabilities that the workers in the platform economy were facing, and this note explores their conditions during the pandemic.

\section{Role of Digital Labour Platforms During COVID-19 Lockdown}

The transportation and delivery platforms played a key role in providing essential services to consumers during the lockdowns, as people were restricted to their homes across the globe. In India, some food delivery platforms, such as Swiggy, also started to deliver groceries and essential items. ${ }^{1}$ These services were increasingly vital for those in quarantine, while also providing an important option to those particularly vulnerable to COVID-19 to access food, groceries, goods and even medical services. The workers providing such services also played an important role in connecting consumers with enterprises, including Small and Medium Enterprises (SMEs), and contributed towards meeting demands and ensuring business continuity. As there are no data available on the number of workers engaged in these platforms, it is difficult to estimate their size, but in most countries across the globe these workers were declared as part of the 'emergency services' during COVID-19 lockdown.

At the same time, there was an increase in online web-based work, such as freelancing and software programming during the pandemic. The Online Labour Index $(\mathrm{OLI}),{ }^{2}$ which tracks workers and all the projects and tasks posted on the five largest English-language online web-based labour platforms, shows that since the COVID19 pandemic outbreak, the demand for such tasks declined globally in March 2020 before picking up by the end of April 2020 (see Fig. 1). The global decline from mid-March to mid-April in 2020 was quite steep compared to 2018-19, and it is possible that due to the uncertainty caused by COVID-19 pandemic, firms were postponing the outsourcing of tasks or projects. Stephany et al. (2020) posit that due to declining revenues firms might be reducing their non-essential spending, including outsourcing.

\footnotetext{
1 https://www.businesstraveller.com/business-travel/2020/04/13/swiggy-starts-grocery-delivery-acros s-india/.

2 The Online Labour Index (OLI) measures the utilization of online labour platforms over time and across countries and occupations (Kässi and Lehdonvirta 2018).
} 


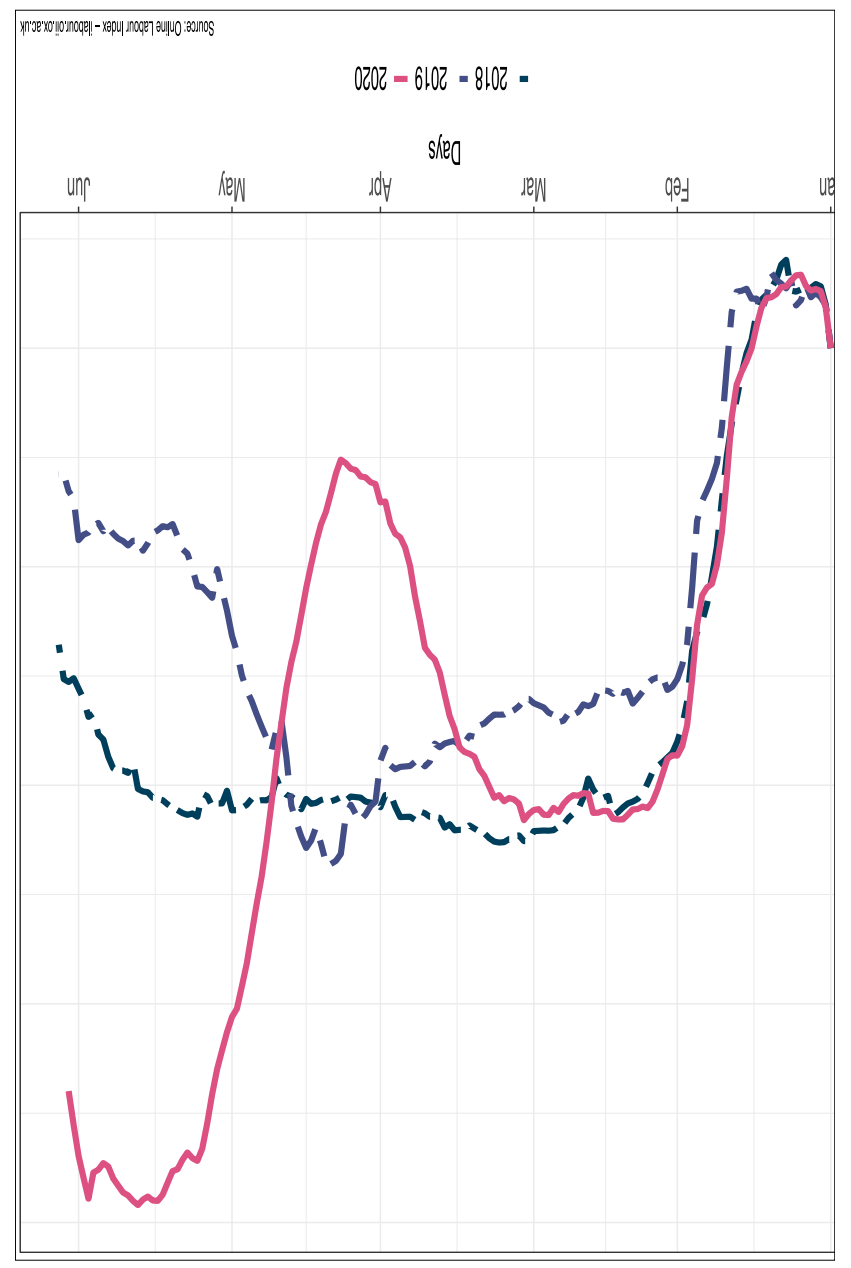

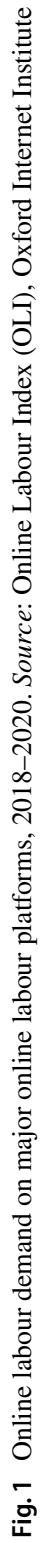




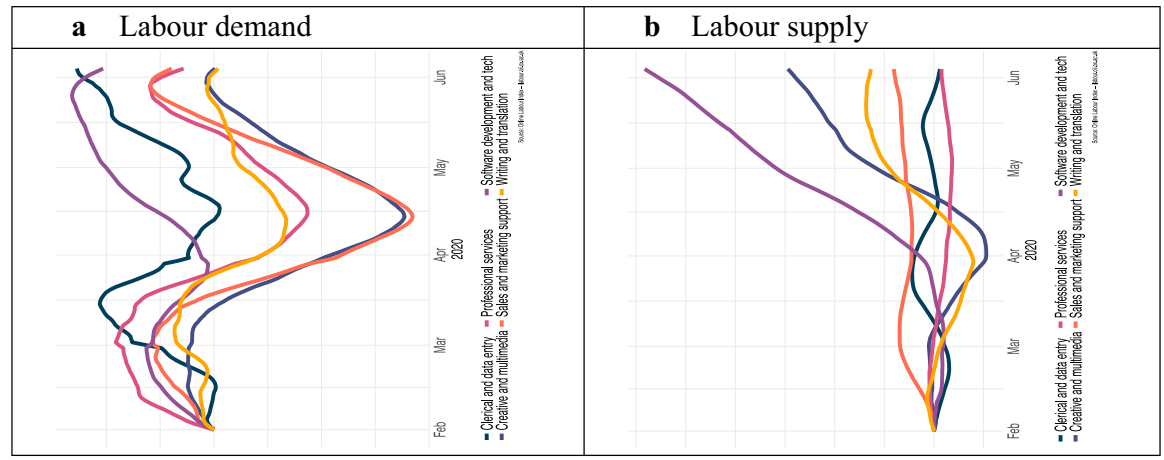

Fig. 2 Online work demand and supply by occupational categories, the USA, 2020. Source: Online Labour Index (OLI), Oxford Internet Institute

The demand for online work globally is dominated by the USA (47\%). However, the demand for online work was quite uneven across different parts of the world during the COVID-19 pandemic. It increased in the UK, Australia, Canada, India and Germany, but declined in the USA. The decline in demand in the USA was observed in activities such as creative and multimedia, clerical and data entry, and writing and translation. India and the UK observed an increase in online work demand, which was largely in the software development and technology activities. The labour supply for online work is dominated by India (33\%), followed by Bangladesh, Pakistan, Philippines and Ukraine, apart from the USA and the UK. The share of total supply of workers coming from India increased during the COVID-19 pandemic, and a marginal increase was also observed in the UK and Ukraine, while it declined in other countries.

To further examine the changing landscape of online platforms during COVID19, we focus on two countries - the USA and India, as they have a large presence in both demand for online work and supply of labour on these platforms. Both online work demand and labour supply in the USA declined between March and April 2020, and it then picked up. The drop in the demand for online work was largely in creative and multimedia, and sales and marketing support (see Fig. 2a, b). However, demand for software development and technology remained quite stable and increased since the beginning of April. Stephany et al. (2020) based on their interviews with freelancers in the USA found that companies are probably cutting their non-essential expenditures related to marketing and sales campaigns, while continuing their business outsourcing related to software development and other technology support, in the context of remote teleworking. On the labour supply side, there was a decline in labour supply across all occupations except software development, and since April 2020 the supply of labour increased quite steeply, in particular in the software development and technology category and at a slow pace for clerical and data entry work (see Fig. 2a, b).

In India, in contrast, both online work demand and labour supply increased in April 2020, after a slight decline during mid-March (see Fig. 3a, b). Compared to earlier years, there was a spike in both demand and supply from April 


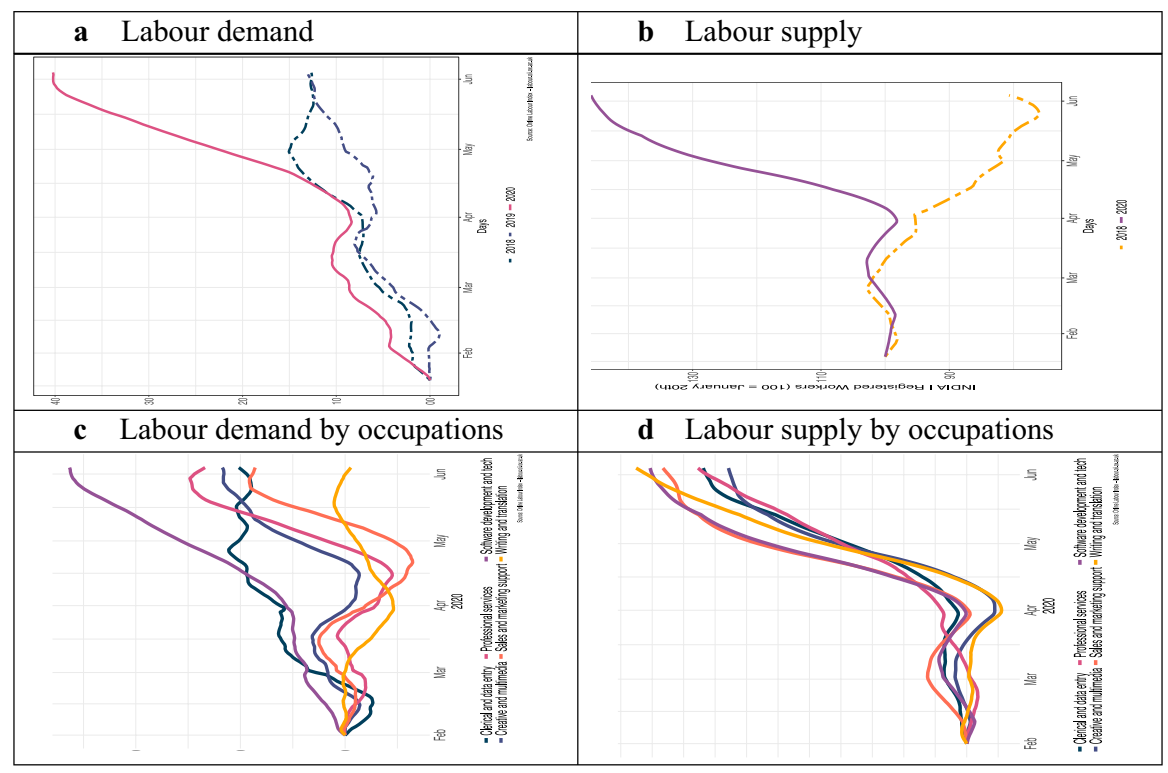

Fig. 3 Online work demand and supply by occupational categories, India, 2020. Source: Online Labour Index (OLI), Oxford Internet Institute

to early June. The increase in the demand for online labour was largely driven by software development and technology in mid-March, which took off immediately, and as mentioned earlier the need for finding software solutions related to remote and teleworking could have led to an increase in these activities (see Fig. 3c). In mid-April, there was also a rise in professional services, and sales and marketing activities. Other occupations such as creative media and clerical activities picked up in mid-May. It is possible that with the decline in revenues many companies in India are looking at online labour platforms as a substitute for on-site work (Stephany et al. 2020).

With the increasing online work demand in India, there is also an increase in the number of registered workers, as it provides opportunities for replacing lost incomes either due to layoffs or insecurities related to their existing working situations. The occupations that have observed the biggest increase in labour supply are software development and technology, for which demand continues to grow, unaffected by the seasonal patterns that were observed in the earlier years clearly indicating that there is an increase in such work locally within the country (see Fig. 3d). While this trend is not surprising, it raises questions about the transformations in the world of work and what it means for both businesses and workers.

There is a very clear indication that with the ICT revolution and the proliferation of the internet, platform work will continue to grow. If the pandemic continues, the pace at which the world of work might transform can be even more rapid, and the increasing insecurities exposed by the pandemic need to be resolved. 


\section{Opportunities and Challenges with Platform Work in the Time of COVID-19}

Platform work is often heralded for the flexibility it offers, the freedom to choose work, its income generation potential and the autonomy available to those performing the work. Research in recent years has raised concerns about low and unstable pay, inadequate access to regular work, lack of paid time off or sick leave, as well as poor or no access to social protection, particularly due to the classification of workers as 'independent contractors' or 'freelancers' (Berg et al. 2018; Huws et al. 2017; Rosenblat and Stark 2016).

Since the COVID-19 outbreak, these concerns have magnified. Workers engaged in location-based platforms such as those providing delivery or taxi services are particularly at risk due to the nature of their work as they cannot always ensure social distancing. ${ }^{3}$ Many workers depend entirely on task-based work for their earnings without paid sick leave, and they cannot afford to self-quarantine even if COVID-19 symptoms were to appear, posing risks to both themselves and others. At the same time, with the lack of health insurance coverage for platform workers in many countries, even getting tested for COVID-19 may be challenging. ${ }^{4}$ This could lead to a scenario wherein not only is the platform worker engaged in work while being sick, but also risks spreading the virus to the customers or businesses involved. While risks of contracting COVID-19 is less for workers engaged in online platforms when compared to those engaged in location-based platforms, limited access to social protection creates challenges for them too.

As the levels of unionization among these platform workers are low, there are limited avenues for collective bargaining in the platform economy. Despite that, many of them have formed informal groups or associations and are fighting for their rights, especially related to 'mis-classification' as they are classified as 'independent contractors', 'self-employed' or 'freelancers', which excludes them from getting any labour or social protection. The lack of such protections are exposing workers to additional risks in the context of COVID-19 pandemic, as the workers are often not provided with personal protective equipment, or sick pay or hazard pay for performing tasks. In the absence of institutionalized mechanism for collective bargaining, some workers have also resorted to strike actions to demand for basic protections such as provision of Personal Protective Equipment (PPE) and hazard pay, among others. ${ }^{5}$ In addition, workers have also been demanding platform companies to provide access to their administrative data to public authorities not only to process unemployment benefits, but also to ensure that workers are not crowding at certain pick points so as to avoid the spread of the virus. These workers have also been demanding government authorities to provide them with unemployment and social protection benefits, as they are included as 'essential workers', and to expand

\footnotetext{
3 https://oecd-development-matters.org/2020/03/27/from-social-distancing-to-social-solidarity-gigeconomy-and-the-covid-19/.

4 https://torontosun.com/news/local-news/braun-gig-economy-and-coronavirus-match-made-in-hell.

5 https://techcrunch.com/2020/03/30/instacart-shopper-coronavirus-strike-response/.
} 
the coverage of other benefits such as access to credits with low interest rates, the easing of educational debts, payment of cash transfers, among others.

Platform app companies have been responding in various ways, depending upon the company and the country to the workers' demands, for instance, using the app to effectively communicate the measures adopted by the company and by the regulatory authorities, including global guidelines to prevent the spread of the virus. They have also tried to provide hand sanitizer, masks or air sprays to prevent workers and consumers from infecting or spreading the virus. ${ }^{6}$ Moreover, they have also set up special places for disinfecting vehicles, motorbikes, bikes, backpacks or food containers, either by their own initiative, in consultation with platform workers' associations, or in coordination with public authorities. ${ }^{7}$ However, several reports and press chronicles have shown that many workers are not receiving this equipment, due to logistic difficulties or problems of shortage. ${ }^{8}$ Some app companies have set up emergency funds and other forms of sick pay to assist workers infected with the virus or that have been medically ordered to self-isolate. ${ }^{9}$ However, these sick pay schemes are considered to be insufficient to cover the loss of income and even distant from minimum wages available in different countries. ${ }^{10}$

Public authorities have responded across the world with preventive health and safety measures such as providing information and training in relation to COVID19 and providing protective equipment (such as Brazil, Chile, Colombia, Valencia in Spain, Peru). Some countries such as Peru have also provided paid sick leave for those infected with virus or in close contact with infected people from the common fund and special private insurance and most importantly have passed a bill which also provides for sharing of data to prevent agglomeration. While these are important measures, they are not sufficient to address the risks that these platform workers face.

\section{Sustainability of Platform Business and Need for Regulations}

The COVID-19 pandemic has also exposed the sustainability of platform business, as many of these companies were already struggling to be profitable. For instance, Uber reported losing US\$ 5.2 billion $^{11}$ in its second quarterly earnings in 2019,

\footnotetext{
${ }^{6}$ http://www.leparisien.fr/economie/uber-commence-a-equiper-ses-chauffeurs-de-masques-10-04-20208297355.php.

7 https://www.munistgo.cl/municipalidad-de-santiago-y-didi-realizan-sanitizacion-gratuita-para-taxis -en-santiago/.

${ }^{8}$ https://thewire.in/business/covid-19-food-delivery-workers.

9 https://www.uber.com/blog/update-covid-19-financial/; https://fair.work/fairwork-releases-report-onplatform-responses-to-covid-19/ (nearly half the of the platforms surveyed by Fairwork launched some form of sick pay, although they "do not typically label the financial support provided as "sick pay" but instead describe it as "a one-time pay adjustment" or as "a support payment"”.); https://www.jorna da.com.mx/ultimas/mundo/2020/03/12/didi-crea-fondo-de-emergencia-para-conductores-contagiados-decovid-19-6304.html.

10 https://fair.work/fairwork-releases-report-on-platform-responses-to-covid-19/.

11 https://www.theverge.com/2019/8/8/20793793/uber-5-billion-quarter-loss-profit-lyft-traffic-2019.
} 
Swiggy's losses grew sixfold to ₹2367 crore in the financial year 2019, ${ }^{12}$ and Zomato posted US\$294 millions in losses for the financial year $2019 .{ }^{13}$ Despite their non-profitability, venture capitalists continue to heavily subsidize them and they are betting on these platforms to dominate the market with network effects, which will lead to significant returns for their investments, the popular 'winner-takes-all' argument (Kenney and Zysman 2018, pp. 12-13). These companies seem to have used the pandemic to also cut costs by laying off workers; for instance, Swiggy laid off 1100 employees and Ola 1400 employees, which also helps them to restructure their companies.

Some companies such as Uber are also using this crisis as an opportunity to change their business model, shifting from a specific economic activity to a more massive scale and coordinating gig work. Uber has launched a new 'Work Hub' that enables its drivers to find alternative gig work, in such areas as customer service, food production and logistics. Through this Hub, app-based drivers can connect with other Uber platforms, such as Uber Eats (food deliveries), Uber Freight (trucking) and Uber Works (blue-collar shifts), and with a growing number of companies that have entered in agreements with Uber. As put by a recent press report, Uber is '... becoming a platform for organising all kinds of casual, temporary and gig work. And by extension, it's becoming a platform for transforming work in general, for making work more casual and temporary, and for making labour more flexible. ${ }^{14}$

The regulation of digital platforms has been under discussion in several countries, with debates underway particularly regarding the role of regulatory frameworks for ensuring labour protections on digital labour platforms. Recognizing these difficulties, the ILO's Global Commission on the Future of Work called for the 'development of an international governance system for digital labour platforms (and their clients) to respect certain minimum rights and protections' (ILO 2019, p. 13). It could set minimum standards as well as develop the infrastructure necessary for facilitating payments to social security systems, and it could also establish a representative board to adjudicate disputes between platforms, clients and workers. Given the critical role of social dialogue, access to healthcare, income stability, paid leave and sick leave, and social protection more broadly in combating the spread of COVID-19, the evolving world of work under the platform economy model requires an urgent and serious transformation for ensuring both short- and long-term economic stability and sustainability.

\footnotetext{
${ }^{12}$ https://www.livemint.com/companies/news/swiggy-s-losses-rise-six-fold-to-rs-2-367-crore-in-fy1911576477188331.html.

13 https://economictimes.indiatimes.com/small-biz/startups/newsbuzz/zomato-posts-usd-294-mn-lossfor-fy19-revenue-up-3-fold-to-usd-206-mn/articleshow/68743020.cms.

${ }^{14}$ https://www.forbes.com/sites/simonchandler/2020/04/07/coronavirus-turns-uber-into-gig-platformfor-all-work/\#63052fb31db9.
} 


\section{References}

Berg, Janine, Uma Rani, Marianne Furrer, Ellie Harmon, and M. Six Silberman. 2018. Digital Labour Platforms and the Future of Work. Geneva: International Labour Organization.

Evans, P. C., and Annabelle Gawer. 2016. The Rise of the Platform Enterprise: A Global Survey. Report. The Center for Global Enterprise. http://epubs.surrey.ac.uk/811201/. Accessed 8 Aug 2020.

Hagel, John. 2015. The Power of Platforms. Business Trends Series. London: Deloitte University Press.

Huws, U., N. Spencer, D. Syrdal, and K. Holts. 2017. Work in the European Gig Economy: Research Results from the UK, Sweden, Germany, Austria, the Netherlands, Switzerland and Italy. Hertfordshire: FEPS, UniGlobal and University of Hertfordshire.

International Labour Office (ILO). 2019. Global Commission on the Future of Work: Working for a Brighter Future. Geneva: ILO.

Kässi, Otto, and Vili Lehdonvirta. 2018. Online Labour Index: Measuring the Online Gig Economy for Policy and Research. Technological Forecasting and Social Change 137: 241-48. https://doi. org/10.1016/j.techfore.2018.07.056.

Kenney, Martin, and John Zysman. 2018. Work and Value Creation in the Platform Economy. Berkeley Roundtable on the International Economy Working Paper 2018-4. Berkley, University of California.

Rosenblat, Alex, and Luke Stark. 2016. Algorithmic Labor and Information Asymmetries: A Case Study of Uber's Drivers. International Journal of Communication 10: 3758-3784.

Stephany, Fabian, Michael Dunn, Steven Sawyer, and Vili Lehdonvirta. 2020. Distancing Bonus or Downscaling Loss the Changing Livelihood of US Online Workers in Times of COVID-19. Journal of Economic and Social Geography 111 (3): 561-573.

Teece, David J. 2017. Dynamic Capabilities and (Digital) Platform Lifecycles. Entrepreneurship, Innovation, and Platforms 37: 211-225. https://doi.org/10.1108/S0742-332220170000037008.

UNCTAD. 2019. Digital Economy Report 2019: Value Creation and Capture: Implications for Developing Countries. UNCTAD/DER/2019. Geneva, Switzerland.

Publisher's Note Springer Nature remains neutral with regard to jurisdictional claims in published maps and institutional affiliations. 